\title{
Bajo el sol ardiente y la lluvia torrencial. Viajeros extranjeros y clima colombiano en el siglo XIX*
}

\section{Resumen}

Después de la independencia y a lo largo del siglo XIX, muchos extranjeros estuvieron en Colombia y publicaron sus relatos de viaje. La experiencia para estos viajeros de latitudes medias, en las tierras bajas de un país tropical, fue casi una pesadilla. Sus descripciones resaltan el calor insoportable, la humedad, los mosquitos, las enfermedades y "la pereza" de los pobladores de estos entornos. Su percepción iba cambiando mientras remontaban los Andes y encontraban lugares donde la temperatura decrecía. Entonces, se sentían en una especie de "eterna primavera" o "perpetuo otoño". Este artículo presenta una reconstrucción de percepciones extranjeras sobre el estado del tiempo y el clima, y de registros relevantes para el estudio de la Historia Climática en Colombia.

\section{Palabras clave}

Autores: clima, condiciones meteorológicas, climatología, Colombia-Historia, literatura de viajes, Historia de las ciencias.

Referencia bibliográfica para citar este artículo: Mora Pacheco, Katherinne y Cortes Guerrero, José David. "Bajo el sol ardiente y la lluvia torrencial. Viajeros extranjeros y clima colombiano en el siglo XIX". Anuario de Historia Regional y de las Fronteras 26.2 (2021): 137-164.

Katherinne Mora Pacheco: Doctora en Historia por la Universidad Nacional de Colombia. Profesora asistente de la Escuela de Ciencias Sociales y de la Maestría y Doctorado en Historia de la Universidad Pedagógica y Tecnológica de Colombia. Correo electrónico: katherinne.mora@uptc.edu.co. Código ORCID: 0000-0001-8483-3728.

José David Cortes Guerrero: Doctor en Historia por el Colegio de México. Profesor asociado del Departamento de Historia de la Universidad Nacional de Colombia. Correo eletrónico: jdcortesg@unal. edu.co. Código ORCID: 0000-0002-2581-7442.

\footnotetext{
* El artículo es resultado de varios proyectos de investigación desarrollados como docentes de las instituciones a las cuales los autores se encuentran vinculados: i) Katherinne Mora: proyectos "Conmociones bajo un 'cielo conspirador'. Perturbaciones meteorológicas entre los albores y postrimerías de la independencia, Altiplano Cundiboyacense, 1778-1828” y "El camino antiguo Santafé - Tunja: un puente entre pasado y presente". La autora agradece los comentarios en la socialización de avances en el VII Simposio de Historia regional y Local (Bucaramanga, octubre de 2018), el 3rd World Congress of Environmental History (Florianópolis, julio de 2019) y el XIX Congreso Colombiano de Historia (Armenia, octubre de 2019); ii) José David Cortés Guerrero: proyecto "Viajeros y escritos de viaje en Colombia en el siglo XIX". Código HERMES 47006, Universidad Nacional de Colombia.
} 


\title{
Under the Burning Sun and Pouring Rain. Foreign Travellers and the Colombian Weather Throughout the Nineteenth-century
}

\begin{abstract}
After independence, and throughout the Nineteenth-century, many foreign travelers arrived in Colombia and published their travel accounts. The experience for the mid-latitude travelers, in the lowlands of a tropical country, was almost a nightmare. Their descriptions highlighted the unbearable heat, the humidity, the mosquitoes, the diseases, and "the laziness" of the inhabitants of this kind of environment. Their perception was changing while they climbed the Andes and found places where the temperature decreased. Then, they felt in a kind of an "eternal spring" or a "perpetual autumn". This paper displays a reconstruction of foreign perception on climate and weather and, relevant records to the study of Climate History in Colombia.
\end{abstract}

Keywords

Author: Climate, Weather, Climatology, Colombia-History, Travel Literature, History of Sciences.

\section{Sob o sol escaldante e a chuva torrencial. Viajantes estrangeiros e clima colombiano no século XIX}

\section{Resumo}

Após a independência e ao longo do século XIX, muitos estrangeiros visitaram a Colômbia e publicaram suas histórias de viagens. A experiência para esses viajantes de latitudes médias, nas terras baixas de um país tropical, foi quase um pesadelo. Suas descrições destacam o calor insuportável, a umidade, os mosquitos, as doenças e a "preguiça" dos habitantes desses ambientes. Sua percepção foi mudando conforme eles escalavam os Andes e encontravam lugares onde a temperatura diminuía. Então, eles se sentiram em um tipo de "primavera eterna" ou "outono perpétuo". Este artigo apresenta uma reconstrução das percepções estrangeiras sobre o tempo e o clima, e registros relevantes para o estudo da História Climática na Colômbia.

\section{Palabras chaves}

Autor: clima, condições do tempo, climatologia, História colombiana, literatura de viagem, História da ciencia. 


\section{Introducción}

En las áreas cercanas a la línea del ecuador, una persona proveniente de latitudes medias (aquellas zonas de la Tierra delimitadas por las líneas imaginarias de los trópicos y los círculos polares), acostumbrada a las dinámicas de cuatro estaciones térmicas (primavera, verano, otoño e invierno), notaría con asombro ciertas particularidades del clima. En el caso colombiano, por ejemplo, podría observar que, en un mismo lugar, debido a la insolación directa y permanente, la temperatura promedio no cambia más de $1{ }^{\circ} \mathrm{C}$ a lo largo del año. El principal factor modificador de la temperatura es la altitud, pues, a medida que ascendemos en metros sobre el nivel del mar ( $\mathrm{msnm})$ desciende la marca en el termómetro, esto es, baja la temperatura. Este fenómeno ha dado lugar a los llamados pisos térmicos, conocidos mejor como pisos bioclimáticos o microclimas de altitud (ver figura 1). A lo largo del año, en cambio, sí varía el volumen y la intensidad de las precipitaciones. Una especie de cinturón climático, conocido como Zona de Convergencia Intertropical (ZCIT), fluctúa sobre las zonas cercanas a la línea ecuatorial con cada equinoccio y solsticio (los momentos del año que también marcan el inicio de las estaciones en latitudes medias). Esta oscilación incide en el aumento y la disminución de las precipitaciones, que puede dar lugar a la diferenciación clara de uno o dos periodos secos y lluviosos a lo largo del año, según las particularidades regionales. Esta dinámica puede variar en términos interanuales por un fenómeno aperiódico del Océano Pacífico conocido como El Niño/Oscilación del Sur (ENOS), y sus fases cálida y fría conocidas como El Niño y La Niña, respectivamente. ${ }^{1}$

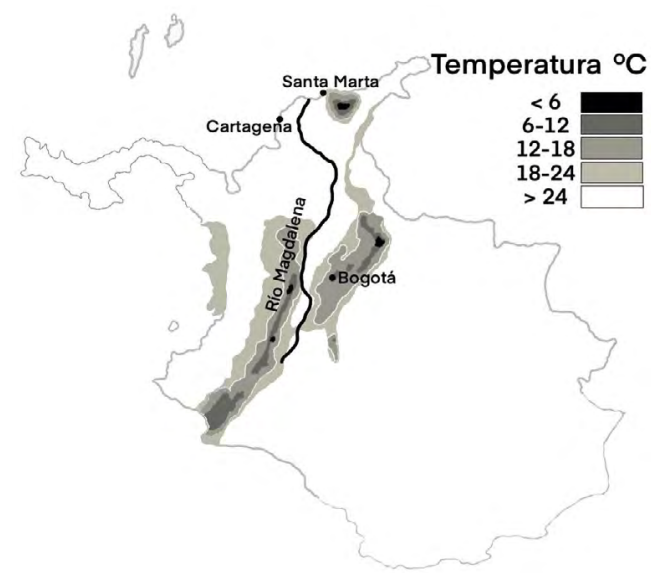

Figura 1. Descenso de la temperatura con la altitud en el territorio colombiano, mediados del siglo XIX.

Fuente: Elaboración de Catalina Mora Pacheco con base en información suministrada por los autores.

\footnotetext{
${ }^{1}$ Para más información sobre el clima colombiano y la variabilidad intraanual e interanual, véase, por ejemplo Ernesto Guhl, Colombia. Bosquejo de su geografia tropical. Vol.1 Geografia Física (Edición Conmemorativa). (Bogotá: Universidad Nacional de Colombia - Universidad de los Andes - Jardín Botánico de Bogotá José Celestino Mutis, 2016); José Daniel Pabón Caicedo y Germán Torres, "Impacto socioeconómico de los fenómenos El Niño y La Niña en la Sabana de Bogotá durante el siglo XX”, Cuadernos de Geografia 16 (2007): 81-94; Germán Poveda, Peter Waylen, y Roger S Pulwarty, “Annual and inter-annual variability of the present climate in northern South America and southern Mesoamerica", Palaeogeography, Palaeoclimatology, Palaeoecology 234, 1 (2006): 3-27.
} 
Estas mismas condiciones climáticas y su relación con los cambios de vegetación y fauna captaron la atención de los viajeros extranjeros que visitaron el territorio colombiano a lo largo del siglo XIX (ver tabla 1). Una primera oleada de visitantes extranjeros llegó en la década de 1820, sobre todo, con miras a establecer relaciones diplomáticas y comerciales en un campo antes acaparado por España. ${ }^{2}$ Aunque esporádicamente llegaron otros extranjeros, la segunda oleada empezó a mitad del siglo XIX y se intensificó, en una tercera ola, hacia las décadas de 1880 y 1890 , en el marco de las bonanzas agroexportadoras. ${ }^{3}$ La mayoría de los viajeros seguía la misma ruta: entrar por la costa Caribe, navegar por el río Magdalena hasta Honda e instalarse en Bogotá, desde donde efectuarán excursiones esporádicas a otros lugares del país.

Tabla 1. Algunos viajeros extranjeros por el actual territorio colombiano, 1822-1898

\begin{tabular}{|c|c|c|c|}
\hline Viajeros & Origen & Años de estadía & $\begin{array}{c}\text { Objetivo reportado del } \\
\text { viaje }\end{array}$ \\
\hline William Duane & $\begin{array}{l}\text { Irlanda (residente en } \\
\text { Estados Unidos) }\end{array}$ & $1822-1823$ & $\begin{array}{c}\text { Cobro de deudas por } \\
\text { apoyo a la independencia. }\end{array}$ \\
\hline Richard Bache & Estados Unidos & $1822-1823$ & $\begin{array}{l}\text { Pariente y compañero de } \\
\text { viaje de William Duane. }\end{array}$ \\
\hline $\begin{array}{l}\text { Jean Baptiste } \\
\text { Boussingault }\end{array}$ & Francia & $1823-1832$ & $\begin{array}{l}\text { Expedición científica } \\
\text { contratada por el } \\
\text { gobierno. }\end{array}$ \\
\hline $\begin{array}{l}\text { Gaspard- } \\
\text { Théodore } \\
\text { Mollien }\end{array}$ & Francia & 1823 & $\begin{array}{c}\text { Exploración (sospechoso } \\
\text { de ser espía enviado por } \\
\text { la Santa Sede). }\end{array}$ \\
\hline $\begin{array}{c}\text { Charles Stuart } \\
\text { Cochrane }\end{array}$ & Inglaterra & $1823-1824$ & $\begin{array}{c}\text { Capitán de la Royal Navy } \\
\text { interesado en explorar } \\
\text { recursos del territorio e } \\
\text { incursionan en extracción } \\
\text { de perlas, pesca y/o } \\
\text { minería. }\end{array}$ \\
\hline John Hamilton & Inglaterra & 1824 & $\begin{array}{c}\text { Establecimiento de } \\
\text { relaciones diplomáticas } \\
\text { y comerciales (misión } \\
\text { oficial). }\end{array}$ \\
\hline Fancis Hall & Inglaterra & $1823-1826$ & $\begin{array}{c}\text { Hidrógrafo contratado por } \\
\text { el gobierno colombiano; } \\
\text { estudia potencialidades } \\
\text { del territorio para atraer la } \\
\text { inmigración. }\end{array}$ \\
\hline
\end{tabular}

\footnotetext{
${ }^{2}$ Mary Louis Pratt indica que los viajeros que recorrieron lo que fueron las colonias españolas una vez obtenida su independencia, esto es en la década de 1820, formaban parte de la vanguardia del capitalismo. Puede verse Mary Louise Pratt, Ojos imperiales. Literatura de viajes y transculturación (México: Fondo de Cultura Económica, 2010), 268-316.

${ }^{3}$ Magnus Mörner, "Viajeros e inmigrantes europeos como observadores e intérpretes de la realidad latinoamericana del siglo XIX", en Observation and Communication: the construction of realities in the Hispanic World (Estocolmo: Institute of Latin American Studies, 2000), 415-30.
} 
Continuación Tabla 1.

\begin{tabular}{|c|c|c|c|}
\hline Viajeros & Origen & Años de estadía & $\begin{array}{l}\text { Objetivo reportado del } \\
\text { viaje }\end{array}$ \\
\hline $\begin{array}{l}\text { Carl August } \\
\text { Gosselman }\end{array}$ & Suecia & $1825-1826$ & $\begin{array}{c}\text { Establecimiento de } \\
\text { relaciones diplomáticas } \\
\text { y comerciales (misión } \\
\text { oficial). }\end{array}$ \\
\hline Charles Empson & Inglaterra & $1825-1827$ & $\begin{array}{c}\text { Botánico y dibujante, } \\
\text { buscaba recorrer los } \\
\text { pasos de Alexander von } \\
\text { Humboldt. Fue secretario } \\
\text { de la mina Santa Ana. }\end{array}$ \\
\hline Joseph Brown & Inglaterra & $\begin{array}{l}1825-1835 / \\
1836-1840\end{array}$ & $\begin{array}{c}\text { Empleado de la } \\
\text { Colombian Mining } \\
\text { Association, dueña de las } \\
\text { minas de Marmato, Santa } \\
\text { Ana y Bucaramanga. }\end{array}$ \\
\hline $\begin{array}{l}\text { August Le } \\
\text { Moyne }\end{array}$ & Francia & $1828-1839$ & $\begin{array}{c}\text { Representante } \\
\text { diplomático del rey } \\
\text { Carlos X. }\end{array}$ \\
\hline John Steuart & $\begin{array}{l}\text { Escocia (residente en } \\
\text { Estados Unidos) }\end{array}$ & $1836-1837$ & Negocios personales. \\
\hline $\begin{array}{l}\text { Miguel María } \\
\text { Lisboa }\end{array}$ & $\begin{array}{c}\text { Brasil (de familia } \\
\text { portuguesa) }\end{array}$ & 1851 & Misión diplomática. \\
\hline Isaac Holton & Estados Unidos & 1852 & $\begin{array}{l}\text { Químico y botánico con } \\
\text { interés por elaborar un } \\
\text { catálogo de flora tropical. }\end{array}$ \\
\hline $\begin{array}{c}\text { José María } \\
\text { Gutiérrez de } \\
\text { Alba }\end{array}$ & España & $1870-1884$ & $\begin{array}{l}\text { Enviado diplomático } \\
\text { para el reconocimiento } \\
\text { de la independencia } \\
\text { por parte de España y } \\
\text { el restablecimiento de } \\
\text { relaciones entre los dos } \\
\text { países. } \\
\end{array}$ \\
\hline Miguel Cané & $\begin{array}{l}\text { Uruguayo (familia } \\
\text { argentina) }\end{array}$ & 1881 & Misión diplomática. \\
\hline $\begin{array}{l}\text { Rosa Carnegie- } \\
\text { Williams }\end{array}$ & Inglaterra & $1881-1882$ & $\begin{array}{l}\text { Esposa de un empresario } \\
\text { minero a quien acompaña } \\
\text { en su estadía en el país. }\end{array}$ \\
\hline $\begin{array}{c}\text { Ernest } \\
\text { Röthlisberger }\end{array}$ & Suiza & $1881-1885$ & $\begin{array}{l}\text { Profesor de filosofia e } \\
\text { historia en la Universidad } \\
\text { Nacional de Colombia. }\end{array}$ \\
\hline Alfred Hettner & Alemania & $1882-1884$ & Estudios geográficos. \\
\hline $\begin{array}{c}\text { Pierre } \\
\text { D'Espagnat }\end{array}$ & Francia & $1897-1898$ & Exploración. \\
\hline
\end{tabular}

Fuente: elaboración propia con base en datos proporcionados en los diarios de viajeros consultados y estudios sobre viajeros. ${ }^{4}$

${ }^{4}$ Camila Torres Torres, "La imagen de Bogotá construida por los viajeros extranjeros que recorrieron el país 
Como se verá, momentos clave de su recorrido por tierras bajas (con altitud inferior a $1000 \mathrm{msnm}$ ), estuvieron atravesados por la incomodidad que generaban el calor y la humedad, relacionadas por ellos con la abundancia de mosquitos atormentadores, las enfermedades tropicales y hasta la poca laboriosidad de la población. Del lado opuesto, cuando ascendían a los Andes, en tierras templadas y frías, y especialmente en Bogotá (a $2600 \mathrm{msnm}$ ) muchos de ellos se sentían en un entorno similar al de sus lugares de origen o residencia y, por esta razón, las calificaban como zonas de civilización y libres de enfermedades. Para ellos, esas tierras altas andinas serían un buen ejemplo para incluir en la órbita de la "Nuevas Europas", denominación acuñada por el historiador Alfred Crosby, lamentablemente restringidas por él solo a las latitudes medias 5 . Para unos pocos, ningún lugar resultó plácido y las lluvias torrenciales, el frío y la ausencia de chimeneas, se convirtieron en motivos de queja. Con incomodidad o sin ella, teniendo en cuenta los fines diplomáticos, comerciales y científicos que persiguieron muchos de los viajeros, fueron comunes interpretaciones sobre la variedad de climas del país como fuente de riquezas y potencialidad del territorio, por ejemplo, para la producción agrícola.

Sus descripciones detalladas, algunas de ellas acompañadas de datos cuantitativos de temperatura, presión o días de lluvia, y de descripciones sobre coyunturas anómalas (por ejemplo, sequías), son de gran utilidad para la Historia del Clima en Colombia. Para el país, contamos con pocos registros cuantitativos decimonónicos, casi todos tomados en la capital, sin instrumentos calibrados, ni medidas estandarizadas, ni referentes similares (por ejemplo, unas veces era precipitación en volúmenes, otras en días de lluvia con indicadores cualitativos como llovizna o torrencial). Algunos de los datos de temperatura y precipitaciones que tenemos son generales y buscan reportar promedios, no muestran especificidades de su recolección y corresponden a los informes de la Comisión Corográfica dirigida por Agustín Codazzi, ${ }^{6}$ y continuada por Felipe Pérez. ${ }^{7}$ La mayoría de los datos continuos corresponden a pocos meses y no llegan a cubrir años completos. ${ }^{8}$ Aunque los datos

a lo largo del siglo XIX" (Tesis de Maestría en Historia, Bogotá, Pontificia Universidad Javeriana, 2009), http://repository.javeriana.edu.co/handle/10554/458; Katherinne Giselle Mora Pacheco, "Monotonía, aislamiento y atraso agrícola. Descripciones de viajeros del siglo XIX e historia agraria de la Sabana de Bogotá (Colombia)", HiSTOReLo. Revista de historia regional y local 7, 14 (2015): 180-213, http://dx.doi. org/10.15446/historelo.v7n14.48625; Giorgio Antei, Guia de forasteros: viajes ilustrados por Colombia, 1817-1857 (Bogotá: Seguros Bolívar, 1995); Jaime Jaramillo Uribe, "La visión de los otros. Colombia vista por observadores extranjeros en el siglo XIX", Historia Crítica, 24 (2003): 7-21; Mario Germán Romero, ed., Bogotá en los viajeros extranjeros del siglo XIX (Bogotá: Alcaldía Mayor de Bogotá - Villegas Editores, 1990); José Luis Díaz Granados, Viajeros extranjeros por Colombia (Bogotá: Presidencia de la República, 1997); Malcom Deas, Efraín Sánchez, y Martínez, eds., Tipos y costumbres de la Nueva Granada. La colección de pinturas formada en Colombia por Joseph Brown entre 1825 y 1841 y el diario de su excursión a Girón, 1834 (Bogotá: Fondo Cultural Cafetero, 1989).

${ }^{5}$ Alfred Crosby, The Columbian exchange: biological and cultural consequences of 1492 (Connecticut: Greenwood Press, 1972).

${ }^{6}$ Agustín Codazzi, Geografia fisica y politica de la Confederación Granadina (Bogotá: Universidad Nacional de Colombia, 2003).

${ }^{7}$ Felipe Pérez, Geografia general fisica y política de los Estados Unidos de Colombia y geografia particular de la ciudad de Bogotá (Bogotá: Imprenta de Echeverría Hermanos, 1883).

${ }^{8}$ Katherinne Mora Pacheco, Entre sequías, heladas e inundaciones. Clima y sociedad en la Sabana de 
cuantitativos sean escasos y discontinuos y por ello no sean útiles para caracterizar continuidades o identificar coyunturas "anómalas", descripciones cualitativas sobre clima y estado del tiempo o sobre diversas presiones hidrometeorológicas, pueden encontrarse en diversas fuentes, entre ellas, la literatura de viaje producida por extranjeros. Estos materiales, que, por supuesto, deben ser objeto de crítica como cualquier fuente, son valiosos porque tienen como punto de partida el nivel de extrañamiento con un medio muy diferente al de su origen, el interés por los recursos naturales, el paso que varios dieron para convertirse en residentes y, en no pocos casos, sus objetivos de investigación científica. Si bien se han hecho investigaciones previas que reconstruyen el perfil de algunos viajeros, sus opiniones sobre la independencia y los procesos políticos, sus percepciones sobre algunas regiones, ciudades, caminos o sectores de la población (indígenas y bogas, por ejemplo), son pocos los trabajos que profundizan en sus visiones sobre la naturaleza, el contexto biofísico y el trópico en general ${ }^{9}$ o sobre la labor de algunos extranjeros en la descripción del clima o el registro meteorológico. ${ }^{10}$ Este artículo busca insertarse en ese vacío historiográfico.

A lo largo del texto se analizarán fragmentos de relatos de viajes realizados por el actual territorio colombiano entre 1822 y 1898, seleccionados no solo debido a sus descripciones explícitas del clima y el tiempo atmosférico, sino, principalmente, porque sus autores procedían de latitudes medias (diferentes países europeos, Estados Unidos, sur de Brasil, Uruguay/Argentina) y, por tanto, eran ajenos a las condiciones climáticas de tierras bajas cercanas a la línea del ecuador. En ese lapso amplio, aunque se ha procurado mantener una coherencia cronológica para el análisis, la prioridad es más bien geográfica y temática, en busca de contrastes entre los puntos de vista de diferentes viajeros o de un mismo visitante frente a diversas zonas del país. Así, teniendo en cuenta la ruta principal de ingreso por los puertos del Caribe y el río Magdalena, una primera sección se enfoca en las percepciones negativas generalizadas sobre las tierras bajas que contrastaban con la comodidad en la cual se sentían al llegar a zonas más altas y frías en los Andes, en puntos como Antioquia o la sabana de Bogotá. Un segundo apartado reconstruye la percepción de algunos viajeros que, por el momento en el cual hicieron su recorrido o por el impacto que les causó, registraron coyunturas vinculadas a las sequías, bien fuera como resultado de fenómenos globales (por ejemplo, ocurrencia de ENOS) o afectaciones de carácter local.

\footnotetext{
Bogotá, 1690-1870 (Bogotá: Universidad Nacional de Colombia, 2019), 66-77, 220, 221; Katherinne Mora Pacheco, "Tras la pista de "terribles veranos" y "copiosas lluvias". Elementos para una historia climática del territorio colombiano", Historia Crítica 74 (2019): 19-40, https://doi.org/10.7440/histcrit74. 2019.02.

${ }^{9}$ Adriano Guerra, "El imperio invisible. Los mosquitos en el Caribe colombiano vistos por los viajeros extranjeros del siglo XIX”, Memorias. Revista digital de Historia y Arqueología desde el Caribe colombiano 41 (2020): 103-29, https://doi.org/10.14482/memor.41.986.1; Simón Uribe Martínez, "Construyendo el trópico: relatos de viajeros ingleses en Colombia durante el siglo XIX”, en Semillas de historia ambiental, ed. Stefania Gallini (Bogotá: Universidad Nacional de Colombia-Jardín Botánico de Bogotá, 2015), 21550; Felipe Martínez-Pinzón, "La mirada invernocular: clima y cultura en Colombia (1808-1924)" (Tesis Doctor of Philosophy, New York, New York University, 2012); Mauricio Nieto, Orden natural y orden social ciencia y política en el semanario del Nuevo Reino de Granada (Bogotá: Universidad de los Andes, 2008); Mauricio Nieto, Paola Castaño, y Diana Ojeda, ““El influjo del clima en los seres organizados” y la retórica ilustrada en el Semanario del Nuevo Reyno de Granada”, Historia Crítica 30 (2005): 91-114.

${ }^{10}$ José Daniel Pabón Caicedo, "El clima de Colombia durante los siglos XVI-XIX a partir de material histórico. Parte I: Inventario de fuentes de información", Cuadernos de Geografía 15 (2006): 75-92; Darío Betancourt Echeverry, Reseña histórica de la meteorología en Colombia (Bogotá: HIMAT, 1982).
} 


\section{El clima colombiano. Entre "infiernos tropicales" y "Nuevas Europas"}

Como la propia experiencia nos ha enseñado, uno de los aspectos que más asombra a los extranjeros sobre el clima colombiano es la ausencia de las cuatro estaciones térmicas. Muchas veces son vanos los esfuerzos por explicar que la temperatura no cambia a lo largo del año, que el día y la noche duran lo mismo y la hora de amanecer y anochecer casi no varían, y que es posible tener diferencias de más de $20^{\circ} \mathrm{C}$ solo ascendiendo y descendiendo por las montañas (ver figura 1).

Esas mismas condiciones eran las que asombraban a los viajeros extranjeros, provenientes de latitudes medias, en el siglo XIX. ${ }^{11}$ A su vez, les asombraba que los nativos no comprendieran las condiciones del clima europeo, como bien ejemplifica el sueco Carl August Gosselman en su registro de conversaciones con los bogas:

Quedaban con la boca abierta cuando les hablaba de nuestros inviernos de hielo y nieve fría, del transporte en trineos y las largas caminatas sobre el agua helada. Para ellos entenderlo era muy difícil y les resultaba incomprensible, pues el único conocimiento que de tales cosas podían tener estaba en las palabras de su idioma, pero no en la práctica o realidad, ya que no conocían la nieve ni habían sentido semejante frío. Lo que más les entretenía era la descripción de las estaciones, ya que las nuestras tienen el triple de duración que las de acá, en tanto que los días de verano son tres veces más largos que los del invierno, y el hecho de que en ciertos lugares no hay noche en verano o en invierno, según corresponda. Ante tales narraciones exclamaban: "Jesús..., tan particular... válgame Dios... qué tierra tan maravillosa”. Sin embargo, no envidiaban esa situación, pues siempre acababan diciendo: "Es mejor aquí". Les agradaba más pelear con los mosquitos. ${ }^{12}$

El ingreso de la mayoría de los viajeros, relacionados en la tabla 2, al territorio de la actual Colombia se hizo por el Caribe y a través del río Magdalena. Un recorrido de varias semanas en el que se mantenían por debajo de los $500 \mathrm{msnm}$, con una temperatura superior a $\operatorname{los} 30^{\circ} \mathrm{C}$. Sus relatos de viaje contienen abundantes referencias sobre el "clima malsano" y sus "miasmas pestilentes" provocadores de fiebres; ${ }^{13}$ la cantidad de mosquitos, que dejaban picadas atormentadoras y que traspasaban hasta

\footnotetext{
${ }^{11}$ La visión inicial que tenían los viajeros al llegar al país es que todo era de grandes dimensiones, monumental, casi monstruoso. Hamilton lo muestra al indicar que "lo que más particularmente llama la atención del viajero al Nuevo Mundo es la condición gigantesca de la naturaleza". John Potter Hamilton, Viajes por el interior de las provincias de Colombia (Bogotá: Presidencia de la República - Colcultura Biblioteca Nacional de Colombia, 1993), 34. Otro británico, Francis Hall, apunta a que el río Magdalena está cubierto, en sus orillas, por "frondosos bosques ... que indican un suelo de fertilidad ilimitada". Francis Hall, Colombia: its present state, in respect of climate, soil, productions, populations, populations, government, commerce, revenue (Londres: Baldwin, 1827), 7.

${ }^{12}$ Carl August Gosselman, Viaje por Colombia, 1825 y 1826, Archivo de la Economía Nacional 41 (Bogotá: Ediciones del Banco de la República, 1981), 147, 148.

${ }^{13}$ Théodore Gaspard Mollien, Viaje por la República de Colombia (Bogotá: Biblioteca Popular de la Cultura Colombiana, 1944), 16; Augusto Le Moyne, Viajes y estancias en la América del Sur. La Nueva Granada, Santiago de Cuba, Jamaica y el Istmo de Panamá (Bogotá: Biblioteca Popular de la Cultura Colombiana, 1945), 38, 91; Miguel Cané, En viaje (Caracas: Biblioteca Ayacucho, 2005), 108, 166.
} 
los toldillos, ${ }^{14}$ y que algunas veces eran acompañados por murciélagos chupasangre; ${ }^{15}$ el calor abrasador, que asimilaban con las temperaturas africanas, ${ }^{16}$ bajo el cual podían quedarse atrapados por falta de prisa de los bogas o por cambios en el caudal del río $;{ }^{17}$ la ausencia total de lluvia interrumpida por fuertes aguaceros ${ }^{18} \mathrm{y}$ tempestades mucho más espantosas que en Europa porque el agua cae a torrentes y con relámpagos "vivos y centelleantes", ${ }^{19}$ esa clase de "lluvia de estilo tropical, que quería, si era posible, reponer de una vez los dos años de sequía". ${ }^{20}$

Por su parte, Miguel María Lisboa, quien fuera embajador del Imperio Brasileño en la Nueva Granada al iniciar la década de 1850, afirmó que en tres aspectos tenía una idea diferente de la navegación por el río Magdalena antes de conocerlo: los mosquitos, los caimanes y las fiebres. Según él, mucho se había escrito sobre "los horrores de estas tres pestes", pero la navegación a vapor, en su caso específico en el barco Manzanares, permitió que más de cien personas viajaran "todas con salud". Sin embargo, la temperatura de la región, específicamente al sur de Magangué, sí era muy alta, superior a $100^{\circ}$ Fahrenheit $^{21}$ (esto es superior a $30^{\circ} \mathrm{C}$ ).

Entre los viajeros había excepciones en cuanto a las quejas por el clima. Por ejemplo, el inglés Charles Empson quien, si bien no negaba que se generaban molestias propias del clima tropical, ello era menos si se comparaban con las ventajas que ofrecía la "región floreciente". ${ }^{22}$ Esto es, el clima pasaba a segundo plano cuando lo que importaba era que había una tierra por ser redescubierta y explotada, como en el caso de Empson quien viajó muy poco tiempo después de la independencia. También el coronel irlando-estadounidense William Duane veía que en la zona cercana a la Costa se presentaban espacios con buen clima, y no el clima malsano que muchos viajeros mostraban. Ejemplo de ello era el poblado de Turbaco, en donde en los meses de más calor, los habitantes acaudalados de Cartagena pasaban la temporada, pues allí era más fresco. ${ }^{23}$

\footnotetext{
${ }^{14}$ Le Moyne, Viajes y estancias en la América del Sur, 27; Mollien, Viaje por la República de Colombia, 58; Gosselman, Viaje por Colombia, 1825 y 1826, 148; John Potter Hamilton, Viajes por el interior de las provincias de Colombia, vol. I, Archivo de la Economía Nacional 15 (Bogotá: Imprenta del Banco de la República, 1955), 147; John Steuart, Narración de una expedición a la capital de la Nueva Granada y residencia allí de once meses (Bogotá en 1836-37) (Bogotá: Academia de Historia de Bogotá - Tercer Mundo Editores, 1989), 70, $76,85$.

${ }^{15}$ Le Moyne, Viajes y estancias en la América del Sur, 27.

${ }^{16}$ Mollien, Viaje por la República de Colombia, 326; Ernst Röthlisberger, El Dorado. Estampas de viaje y cultura de la Colombia suramericana, vol. 1, Apuntes maestros (Bogotá: Universidad Nacional de Colombia, 2016), 55.

${ }^{17}$ Röthlisberger, El Dorado, 1:42; Hamilton, Viajes por el interior de las provincias de Colombia, 1955, I:39.

${ }^{18}$ Gosselman, Viaje por Colombia, 1825 y 1826, 118-20.

${ }^{19}$ Hamilton, Viajes por el interior de las provincias de Colombia, 1955, I:60.

${ }^{20}$ Gosselman, Viaje por Colombia, 1825 y 1826, 43.

${ }^{21}$ Miguel María Lisboa, Relación de un viaje a Venezuela, Nueva Granada y Ecuador (Caracas: Biblioteca Ayacucho, 1992), 188.

${ }^{22}$ Charles Empson, Narratives of South America: illustrating manners, customs, and scenery: containing also numerous facts in natural history, collected during a four years'residence in tropical regions (Londres: Published for the author by W. Edwards, 1836), 19 y ss.

${ }^{23}$ William Duane, Viaje a la Gran Colombia en los años 1822-1823, vol. 2 (Caracas: Instituto Nacional de
} 
En todo caso, para los viajeros con visiones más negativas frente al clima del Caribe y el Magdalena, lo que consideraban un "infierno tropical” iba matizándose a medida que iniciaban la subida a los Andes y experimentaban descensos graduales en la temperatura y observaban cambios en la vegetación y la fauna (especialmente, la paulatina ausencia de los molestos mosquitos). El camino más frecuente para ascender era el que conectaba al puerto de Honda con Bogotá a través de Guaduas y Facatativá; en algunos casos, como los de Gosselman y Le Moyne, la experiencia del cambio respecto al valle del Magdalena se vivió en Antioquia, pero esta no era la generalidad de las experiencias. ${ }^{24}$

En todo caso, sin importar por donde ascendieran, una vez sobrepasaban los $1000 \mathrm{msnm}$ todos notaban la relación entre una mayor altitud y una menor temperatura y tamaño de la vegetación. Una buena síntesis de estas observaciones fue registrada por el suizo Ernst Röthlisberger en la década de 1880:

La situación ecuatorial del país, unida a la presencia de tan enormes cadenas montañosas cubiertas de nieves perpetuas, determina las más diversas gamas o posibilidades climáticas. Según altitudes, predomina el paisaje tropical o el de montaña. Si bien las circunstancias locales de cada sitio dificultan realmente la división, se han distinguido tres grandes regiones: la región alta y fría (tierra fría); la región media y de moderada temperatura (tierra templada), y la región baja y cálida (tierra caliente). ${ }^{25}$

Miguel Cané, quien viajó desde la Costa Caribe hasta el interior, por mera coincidencia con el profesor suizo Röthlisberger, también mostró esa variación de la temperatura al ascender hacia Bogotá: "La temperatura, determinada no ya por la latitud, sino por la elevación, empieza a variar; la transpiración se detiene, ráfagas frescas comienzan a acariciar el rostro, y la presión atmosférica, haciéndose más leve, dificulta un tanto la respiración para el pulmón habituado al aire compacto de la tierra caliente". ${ }^{26}$

La tierra caliente, con temperatura media entre $23^{\circ}$ y $30^{\circ} \mathrm{C}$, es para Röthlisberger aquella que se encuentra por debajo de los 1000 metros, en zonas como el valle del Magdalena y los Llanos; la vegetación que incluye son palmeras, bananos, mangos, caña, tabaco, maíz, arroz, índigo, algodón, caucho, marfil vegetal, vainilla, especies maderables (ceiba, higuerón, guayacán, cedros), plantas medicinales (zarzaparrilla, ipecacuana), y en general conjuntos de selvas, cultivos y pastos. La tierra templada, que compara con Italia a finales de mayo, la ubica entre los 1000 y 2300 metros, en las vertientes de las cordilleras, con temperatura media entre 17 y $23^{\circ} \mathrm{C}$; entre la vegetación destaca todo tipo de flores, con atención en

Hipódromos, 1968), 303.

${ }^{24}$ Le Moyne, Viajes y estancias en la América del Sur, 91, 92; Gosselman, Viaje por Colombia, 1825 y 1826, 168-76.

${ }^{25}$ Röthlisberger, El Dorado, 1:57.

${ }^{26}$ Cané, En viaje, 161. 
las orquídeas, además de la quina, la yuca y arracacha que reemplazan a la papa, maíz, batata, plátano guineo, guadua, caña de azúcar y, especialmente nombra este nivel como "la patria del café". La tierra fría la ubica entre 2300 y 4300 metros, con temperatura media de 5 a $15^{\circ} \mathrm{C}$, que compara con los inicios de la primavera o el otoño en su tierra natal; predominan las herbáceas y leguminosas introducidas como cebada, trigo, alfalfa, avena, trébol, pero también la nativa papa; destaca flores como lirios, claveles, violetas y geranios y árboles como sauces, manzanos, nogales, cerezos y melocotoneros. Por encima de los 3000 metros crece el frailejón y las tierras son deshabitadas, y más allá de los 4300 dice no haber vegetación. ${ }^{27}$

Más allá de este extrañamiento que experimentaban los extranjeros frente a la relación altitud-clima, y que sí era natural para los colombianos, llama la atención cómo, en el ascenso a los Andes, las opiniones de los viajeros sobre el clima del país empezaban a tornarse benévolas. Era en estos puntos donde empezaban a ver menos un trópico indómito y más rasgos de su "civilizada" tierra natal, una especie de "Nueva Europa" 28 que escapó del radar de Alfred Crosby cuando circunscribió estas áreas a las latitudes medias..$^{29}$ Por ejemplo, Le Moyne describe el Valle de Medellín a $1500 \mathrm{msnm}$, como de temperatura primaveral porque su promedio diario se mantiene entre los 19 y $25^{\circ} \mathrm{C}$ y las flores se renuevan constantemente..$^{30}$ Las mismas montañas de Antioquia, pero a la altura del Río Negro, son el lugar donde Gosselman empieza a sentirse cómodo con el clima y anota:

la marcha del sol hacía subir los bellos tonos de esa naturaleza que nos rodeaba. en este momento el pensamiento comenzaba a jugar un papel nostálgico. El clima fresco era muy semejante a nuestros veranos allá en el norte. Era en estas ocasiones cuando me sentía trasladado hasta mi antiguo hogar. Los cortos atardeceres y sus noches oscuras me devolvían a los sueños del trópico, donde trataba, sin éxito, de encontrar las claras noches de verano de mi patria, las que durante aquella parte del año convierten a la naturaleza en una de las más bellas que puedan encontrarse. ${ }^{31}$

Descripciones igualmente favorables suelen encontrarse sobre las poblaciones de Villeta $\left(24^{\circ} \mathrm{C}\right.$ de temperatura promedio y $\left.850 \mathrm{msnm}\right)$ y Guaduas $\left(23^{\circ} \mathrm{C}\right.$ temperatura promedio y $1100 \mathrm{msnm}$ ), paso obligado de los viajeros que ascendían desde las planicies del Magdalena hacía Bogotá. Las líneas escritas por Steuart son claras en cuanto a las bondades del clima en Guaduas: "No tengo palabras con qué

\footnotetext{
${ }^{27}$ Röthlisberger, El Dorado, 1:58.

${ }^{28}$ En efecto, el término Nueva Europa es empleado textualmente por Mollien cuando arriba a la Sabana de Bogotá. Mollien, Viaje por la República de Colombia, 58.

${ }^{29}$ Para Crosby, las Nuevas Europas eran aquellos espacios de latitudes medias donde los europeos, en el avance de sus imperios, se habían instalado para recrear el mundo que habían dejado en sus lugares de origen. Para él, eran Nuevas Europas lugares como Estados Unidos, Argentina y Australia. Sin embargo, Crosby nunca contempló los climas y microclimas andinos que ofrecían condiciones similares a las europeas y donde, en efecto, también se asentaron con éxito. Para más información sobre este concepto ver Crosby, The Columbian exchange: biological and cultural consequences of 1492.

${ }^{30}$ Le Moyne, Viajes y estancias en la América del Sur, 92.

${ }^{31}$ Gosselman, Viaje por Colombia, 1825 y 1826, 207. Cursivas nuestras.
} 
describir las delicias del clima. El termómetro escasamente varía más de dos grados ... y en el transcurso de mi residencia permaneció invariable, con un grado o dos de rango, entre $75^{\circ}$ y $76^{\circ} \mathrm{F}\left(24^{\circ} \mathrm{C}\right)^{\prime \prime 32}$. En cuanto a Villeta, el geógrafo alemán Alfred Hettner, afirmaba que era un lugar privilegiado por los bogotanos para el veraneo, sobre todo en los meses de diciembre y enero, en donde disfrutan unas semanas del "clima de tierra caliente". ${ }^{33}$ Sin embargo, y a pesar de las bondades de los climas cercanos a los bogotanos, se presentaba la paradoja de que a los colombianos no les gustaba mucho el plan de viaje a vacacionar, pues "la naturaleza no les inspira mayor entusiasmo". Los que sí lo hacían, se desplazaban a lugares cercanos, "de clima más caliente", 34

Siguiendo con lo anterior, para evitar el choque que representaría el clima de Bogotá, se aconsejaba reposar algunos días en una de estas poblaciones con temperatura y altitud intermedia. ${ }^{35} \mathrm{Al}$ hacer el viaje en sentido inverso, también se sugería y aplicaba la misma estrategia. ${ }^{36}$ De igual manera, para las épocas de mayores vientos y lloviznas en Bogotá y su Sabana circundante, se aconsejaba imitar a sus residentes que acostumbraban a ir a "temperar" a poblaciones como Guaduas, Villeta y Fusagasugá. ${ }^{37}$

Con todo, muchos viajeros se concentraron en Bogotá o hicieron de la capital su punto de operaciones. Por esta razón, la mayoría de sus descripciones están referidas al clima de la llamada "tierra fría" que representaban Bogotá y su Sabana. La percepción sobre el clima de esta ciudad era ambivalente, incluso cuando se trata de los relatos de un mismo viajero. Pueden también observarse diferencias según el lugar de procedencia. Por ejemplo, Hamilton opinaba que el clima de Bogotá era muy similar al de su natal Inglaterra y lo definía como de primavera perpetua, propicio para el florecimiento de variados y hermosos claveles y hábitat de colibríes a pesar del frío y la altitud; con lluvias que solían presentarse en las tardes y una temperatura que calculaba entre $58^{\circ}$ y $70^{\circ} \mathrm{F}\left(14^{\circ} \mathrm{C}\right.$ y $\left.21^{\circ} \mathrm{C}\right)$, donde no había ni calor ni frío excesivos, era favorable para la complexión de las mujeres. ${ }^{38}$ Aspecto en el que Hettner coincidía, al definir el clima de Bogotá "como de eterna primavera", con fluctuaciones de temperatura insignificantes. ${ }^{39}$ Para él, el clima de Bogotá se asemejaba al de Suiza: "al levantarnos apenas 100 metros sobre la sabana de Bogotá, ya habríamos alcanzado la altura que, en la Suiza septentrional, está demarcando el comienzo de las regiones permanentemente cubiertas de nieve". ${ }^{40}$

\footnotetext{
${ }^{32}$ Steuart, Narración de una expedición a la capital de la Nueva Granada, 94.

${ }^{33}$ Alfred Hettner, Viajes por los Andes Colombianos (1882-1884) (Bogotá: Publicaciones del Banco de la República - Archivo de la Economía Nacional, 1976), 77, 78.

${ }^{34}$ Hettner, 28.

${ }^{35}$ Gosselman, Viaje por Colombia, 1825 y 1826, 290.

${ }^{36}$ Le Moyne, Viajes y estancias en la América del Sur, 349.

${ }^{37}$ Miguel María Lisboa, Relación de un viaje a Venezuela, Nueva Granada y Ecuador (Bogotá: Fondo Cultural Cafetero, 1984), 215.

${ }^{38}$ Hamilton, Viajes por el interior de las provincias de Colombia, 1955, I:83, 104, 105.

${ }^{39}$ Hettner, Viajes por los Andes Colombianos (1882-1884), 32.

${ }^{40}$ Hettner, 9.
} 
Por sus condiciones climáticas, Hamilton notaba que en Bogotá eran raras las enfermedades, pero sí se presentaban fiebres en las personas que venían de tierras calientes y una especie de "mal de insolación" a las mulas que hacían el mismo viaje ${ }^{41}$. Hettner afirmaba que en Bogotá

ausentes están, gracias tanto a la elevación sobre el nivel del mar como a la temperatura fresca, todas las enfermedades propiamente tropicales, tales como las fiebres graves, afecciones al hígado y similares, molestando la malaria común en general solamente a quienes la han adquirido en tierra caliente. Tampoco la tuberculosis afecta a los habitantes de Bogotá, abrigándose en cambio para los tísicos llegados de afuera la esperanza de prolongar su vida o hasta de curarse completamente. ${ }^{42}$

Para el brasileño Lisboa, el clima de Bogotá, debido a su privilegiada altitud sobre el nivel del mar, era "uno de los más saludables del mundo, variando la temperatura de $11^{\circ}$ a $16^{\circ}$ en el termómetro de Réaumur", ${ }^{43}$ esto es 13,75 a $20^{\circ} \mathrm{C}$.

Otros viajeros no siempre apreciaban del mismo modo las bondades del clima de Bogotá y su Sabana, aunque también pueden encontrarse puntos coincidentes. El francés Mollien la denominaba "nueva Europa" y se alegraba de llegar a la altiplanicie porque estaría allí protegido de "insectos y alimañas", pues se trataba de un lugar donde las enfermedades o eran producto de fiebres contraídas en el camino o estaban asociadas a malos hábitos de vida y alimentación. ${ }^{44}$ Esta opinión es compartida por el también francés Le Moyne, pero destacando el mal de altura como una de las afectaciones que sufren los recién llegados. ${ }^{45} \mathrm{~A}$ Mollien le parece que "el cielo está siempre cubierto de nubes, y pocas veces se disfruta de esos días espléndidos que hasta en los inviernos más crudos gozamos en Europa". ${ }^{46}$ Le disgusta la temperatura que se mantiene entre los 6 y $14^{\circ} \mathrm{R}$ (Reaumur) (esto es 7.5 y $17.5^{\circ} \mathrm{C}$ ), y le hace pensar que la Sabana estaba "entristecida por un otoño perpetuo que por una constante primavera". ${ }^{47}$ A pesar del frío, al igual que los habitantes de los páramos donde el frío era glacial pero sus pobladores no prendían fuego, los bogotanos no contaban con chimeneas en sus casas y para proporcionar algo de calor recurrían a los tapetes que, por falta de aseo, solían llenarse de insectos. ${ }^{48}$

Este hecho era también asombroso para Le Moyne, quien resaltaba que ni en las casas de los ricos había chimeneas y "ni siquiera se usa brasero, tan común

\footnotetext{
${ }^{41}$ Hamilton, Viajes por el interior de las provincias de Colombia, 1955, I:85, 150.

${ }^{42}$ Hettner, Viajes por los Andes Colombianos (1882-1884), 33.

${ }^{43}$ Lisboa, Relación de un viaje a Venezuela, Nueva Granada y Ecuador, 1992, 215.

${ }^{44}$ Mollien, Viaje por la República de Colombia, 58, 179.

${ }^{45}$ Le Moyne, Viajes y estancias en la América del Sur, 116.

${ }^{46}$ Mollien, Viaje por la República de Colombia, 178.

${ }^{47}$ Mollien, 58.

${ }^{48}$ Mollien, 86, 87, 181.
} 
en España". ${ }^{49}$ La visión de Le Moyne sobre el clima puede ser aún más completa porque vivió en Colombia más de una década, condición que le daba oportunidad de comparar años normales y atípicos. Para él, mientras no se tratara de los meses más lluviosos (abril-mayo, octubre-noviembre), el clima era como la primavera o el inicio del otoño en París y en cualquier caso apto para producir "todo lo que constituye la principal alimentación de los europeos". ${ }^{50}$

Por su parte, el oficial del ejército estadounidense, Richard Bache, describe el clima de Bogotá como "desagradablemente frío", debido esto a la altura, y a las nubes que se ciernen constantemente "sobre la ciudad y descansan sobre las colinas, cerca de las cuales la ciudad está construida imprudentemente". ${ }^{51}$ El sueco Gosselman, pese a su origen nórdico, advertía sobre el clima de Bogotá que

sin ser insalubre, es uno de los más peligrosos del país, en especial para los extranjeros, y no son pocos los casos que se cuentan de viajeros que acá encontraron el último de sus paseos. El motivo de esto parece ser la brusca interrupción del calor del Magdalena y su cambio por el frío de esta sabana montañosa. Debe advertirse que un cuidado adecuado no está de más en esta tierra, pues el cambio de un clima de treinta y cinco o cuarenta grados por uno de quince o veinte es un riesgo muy grande.

Por ello la enfermedad más común es la fiebre con escalofríos unida a una creciente dificultad para respirar, que, al fin de cuentas, afectará los pulmones. Muchos jovencitos han partido hacia sus tumbas con mayor rapidez de la prevista porque después de haberse salvado de los peligros de las tierras calientes se han descuidado en la sabana bogotana. ${ }^{52}$

Para evitar estas afecciones, además de la ya mencionada medida de detenerse un par de días en Villeta o Guaduas para adecuarse a la temperatura, aconsejaba arroparse lo suficiente con prendas de lana, tomar bebidas para recobrar fuerzas como el vino con quinina y practicar ejercicio adecuado por las alamedas de la ciudad..$^{53}$

A mediados del siglo XIX, en su viaje a la Nueva Granada, el químico Isaac Holton aludía a que el clima influía en el "carácter nacional" ya fuese por medio del vestido o de los productos agrícolas. Sin embargo, era falso que los habitantes de la "Zona Tórrida" fuesen más violentos que las "razas nórdicas". ${ }^{54}$ En cuanto a la temperatura de Bogotá, Holton toma los datos de Boussingault, quien la calculó en $58^{\circ} \mathrm{F}$ promedio anual $\left(14.4^{\circ} \mathrm{C}\right)$, pero creía que el dato de $59^{\circ} \mathrm{F}\left(15^{\circ} \mathrm{C}\right)$ que daba Tomás Cipriano de Mosquera era más acertado. Indicaba que enero y junio eran los meses más fríos y que los meses de lluvia correspondían a los de primavera y otoño

\footnotetext{
${ }^{49}$ Le Moyne, Viajes y estancias en la América del Sur, 115.

${ }^{50}$ Le Moyne, 114.

${ }^{51}$ Richard Bache, Notes on Colombia: taken in the years 1822-3 with an itinerary of the route from Caracas to Bogotá and appendix (Filadelfia: H.C. Carey, 1827), 225.

${ }^{52}$ Gosselman, Viaje por Colombia, 1825 y 1826, 290.

${ }^{53}$ Gosselman, 290.

${ }^{54}$ Isaac Holton, La Nueva Granada: veinte meses en los Andes (Bogotá: Ediciones del Banco de la República, 1981), 21, 22.
} 
en Estados Unidos. Afirmaba que la gente estaba acostumbrada al frío y a quien le molestara, salía al aire libre para después quejarse del calor. En cuanto a la humedad, para él, Bogotá era seca, con pocos días de lluvia, uno de cada tres. En su experiencia, Holton indicaba que, en cuanto a días, los meses más lluviosos son marzo con 20 , abril con 18 , mayo con 20 y junio y diciembre con 10. Las "tempestades" eran pocas y para encontrarlas en gran número era necesario ir al Chocó. ${ }^{55}$

Tres décadas después, en la tercera oleada de viajeros, el suizo Röthlisberger afirma que

el extranjero que, después de un largo y costoso viaje, llega a la sabana de Bogotá experimenta, antes que todo, una justificada sorpresa. Se ha dicho con acierto que la impresión que recibe una persona en tales circunstancias debe de parecerse a lo que se sentiría al pasar rapidísimamente de una selva del centro de África a una llanura de la Normandía. ¿Cómo es posible que tan penosos caminos conduzcan a una de las más importantes ciudades de Suramérica, donde habitan tantas personas ricas y cultas y donde se acumulan tantos capitales y tantos tesoros del espíritu? Ya en esto se muestra que Colombia es un país de violentos contrastes. ${ }^{56}$

Sobre Bogotá, que es donde más tiempo reside, Röthlisberger aclara que no hay sino dos estaciones: seca (diciembre-enero y junio-agosto) y lluviosa (febreromayo y septiembre-noviembre). De las temporadas lluviosas, lo que más le asombraba era que no llovía continuamente, sino que se sucedían

violentas precipitaciones en forma de aguaceros entre truenos y relámpagos. Durante una hora el cielo suelta todas sus esclusas; luego, por lo común, aclara completamente. Solo una vez, en toda mi permanencia, llovió ininterrumpidamente en Bogotá durante unas treinta y seis horas. A veces cae también granizo de gran tamaño, así que algunos de los cerros que dominan la ciudad quedan revestidos de blancor, bajando mucho la temperatura. Un día vi en los patios de varias casas una capa de granizo de un pie de espesor. Es curioso anotar que la gente pobre recoge el producto de la granizada, y entonces hay helado en Bogotá, pero no procedente de ninguna fábrica de hielo. ${ }^{57}$

Röthlisberger observaba, como es de experiencia aún hoy para los bogotanos, que esas temporadas secas y lluviosas no eran radicales, sino que en las temporadas secas se presentaban lloviznas y llegadas de masas de aire frío, y que las épocas lluviosas a veces tardaban en presentarse, provocando la debilidad y bajo peso de los ganados; con todo, recuerda que los cielos más azules se observaban en la temporada seca de diciembre y enero. ${ }^{58}$ En cuanto a la comparación de otros viajeros con las estaciones de latitudes medias, Röthlisberger advertía que los extranjeros no debían creer que vivían en una eterna primavera y debían prevenirse de las dificultades que

\footnotetext{
${ }^{55}$ Holton, 285-87.

${ }^{56}$ Röthlisberger, El Dorado, 1:55.

${ }^{57}$ Röthlisberger, 1:73.

${ }^{58}$ Röthlisberger, 1:74, 75.
} 
representaba venir de zonas tórridas a una Sabana de aire frío que puede rápidamente pasar de muy seco a extremadamente húmedo, menor presión atmosférica que representa dificultades para respirar al foráneo por los primeros ocho días, fuertes vientos y aguaceros, temperatura a la sombra y al descubierto que podía llegar a diferenciarse en $15^{\circ} \mathrm{C}$. La suma de estas condiciones, aunque impedía el desarrollo de la fiebre amarilla, sí aumentaba la frecuencia de resfriados y catarros, e incluso por pulmonía había muerto más de un "vigoroso extranjero", razones que le llevaban a recomendar usar siempre sobretodo y mantener "estricta higiene". ${ }^{59}$ Por último, una de las condiciones que más le llamaba la atención del clima capitalino (compartida también por el territorio nacional) era la igual duración del día y la noche (de 6 a 6), a la que manifiesta haberse adaptado pronto y que consideraba de gran beneficio para los miopes. ${ }^{60}$

Un viajero contemporáneo a Röthlisberger, el alemán Alfred Hettner, uno de los pioneros de la geografía moderna, afirmaba que los extranjeros encontraban en Bogotá, como en las regiones de "tierra alta", un "clima adecuado para su constitución", es decir, para sus organismos y para desarrollar sus actividades, en cambio sufrían mucho con el calor de la "tierra baja" por la fiebre, la disentería y "enfermedades del hígado y otras". ${ }^{61}$

Más de una década después, el francés Pierre D’Espagnat aludía a las noches frías de Bogotá para las que era necesario el empleo de un abrigo si se quería salir a la calle. Ese frío era característico de lo que él llamaba "tiempo de páramos", es decir, neblinas mezcladas con llovizna, que envolvían a Bogotá y que él describió con esta metáfora: "El cielo de algodón, parece bajar a nivel de los tejados". ${ }^{2}$

Independiente de la percepción sobre el clima de tierras bajas y tierras altas y los paralelos que pudieron establecer, los mismos fines que traían a los viajeros al país, se tratara de inversionistas particulares, enviados por alguna compañía o comisionados diplomáticos de sus países para establecer o fortalecer relaciones diplomáticas o comerciales, los llevaban a destacar la relación entre clima y recursos. Justamente la diversidad de microclimas y los contrastes detectados en sus recorridos llevaron a los viajeros a destacar la posibilidad de producir no solo todo aquello que crecía en Europa, para el caso de la "tierra fría", sino variedad de frutos que vieron cultivados y en las plazas de mercado de las principales ciudades. Algunos, como es aún en el presente, les parecían completamente exóticos y debían establecer comparaciones para sus lectores que no hacían justicia a la belleza de las flores, los sabores y olores de mangos, guanábanas, bananos, piñas, melones, aguacates, cafetos, vainillas, cacaotales, a los poderes curativos de plantas como la zarzaparrilla o la ipecacuana, o a los usos de materias primas como el marfil vegetal, el tabaco, el

\footnotetext{
${ }^{59}$ Röthlisberger, 1:78, 79.

${ }^{60}$ Röthlisberger, 1:79.

${ }^{61}$ Hettner, Viajes por los Andes colombianos, 33.

${ }^{62}$ Pierre D’Espagnat, Recuerdos de la Nueva Granada (Bogotá: Ediciones Guadalupe, 1971), 104.
} 
algodón, el índigo, el guayacán, entre otros. ${ }^{63}$ Por qué las condiciones descritas no se tradujeron en proyectos productivos o inmigración masiva de agricultores, es una cuestión que compete a otras investigaciones. Sin embargo, es de resaltar este reconocimiento de potencialidades en el territorio.

Además de estos rasgos generales y permanentes del clima colombiano, algunos viajeros coincidieron con coyunturas relacionadas con sequías. ¿Cuáles eran sus observaciones?

\section{Las sequías a través de ojos foráneos}

Varios de los viajeros seleccionados para este estudio consideraron importante registrar lluvias torrenciales, acompañadas de relámpagos o granizadas, con volúmenes que no habían visto en sus lugares de origen. ${ }^{64}$ Frente a estas condiciones meteorológicas, además del fenómeno en sí mismo, llamaba su atención las estrategias que usaba la población para protegerse de los aguaceros. Por ejemplo, Gosselman relata cómo, en el camino de Santa Marta a Cartagena,

Los dos indígenas que me acompañaban se desnudaron y después de guardar sus ropas bajo la montura cabalgaron, siendo su alto y ancho sombrero de paja lo único que les cubría y que cual paraguas les protegía escasamente la cabeza de las enormes cantidades de agua que caían.

No consideré bueno su ejemplo, por lo que decidí envolverme en una capa corta de cuero que con paraguas y un sombrero de raíces de anchas alas hicieron todo lo posible por resistir a la lluvia. A los pocos instantes comprobé la insuficiencia de mis defensas, pues cuando el diluvio acabó los acompañantes se colocaron sus ropas secas; en cambio, las mías estaban totalmente mojadas, por lo que tuve que mudarlas. ${ }^{65}$

En Cartagena, observa que, después de dos años de sequía, el volumen de lluvia fue suficiente para llenar los estanques que las personas tenían en sus casas como reservorios para tiempos de escasez. ${ }^{6}$ Por su parte, Hamilton, a pesar del paralelo que establece con Inglaterra, pronto descubre cuán inútil resulta su abrigo de paño por el peso que adquiría después de aguaceros que no se veían en Europa; en

\footnotetext{
${ }^{63}$ Charles Stuart Cochrane, Journal of a residence and travels in Colombia during the years 1823 and 1824, vol. 1 (Londres: Henry Colburn, 1825), 176; Rosa Carnegie-Williams, Un año en los Andes o aventuras de una lady en Bogotá (Bogotá: Tercer Mundo Editores - Academia de Historia de Bogotá, 1990), 53, 69; Gosselman, Viaje por Colombia, 1825 y 1826, 269; Jean Baptiste Boussingault y Francois Desiré Roulin, Viajes cientificos a los Andes ecuatoriales o colección de memorias sobre física, química é historia natural de la Nueva Granada, Ecuador y Venezuela, trad. Joaquín Acosta (Bogotá: Instituto Colombiano de Cultura Hispánica, 1849), 159-71; Le Moyne, Viajes y estancias en la América del Sur, 92, 127; Röthlisberger, El Dorado, 1:57, 58.

${ }^{64}$ Gosselman, Viaje por Colombia, 1825 y 1826, 43, 73, 118-20; Boussingault y Roulin, Viajes científicos a los Andes ecuatoriales, 19; John Potter Hamilton, Viajes por el interior de las provincias de Colombia, vol. II, Archivo de la Economía Nacional (Bogotá: Imprenta del Banco de la República, 1955), 11, 74; Röthlisberger, El Dorado, 1:73.

${ }^{65}$ Gosselman, Viaje por Colombia, 1825 y 1826, 73.

${ }^{66}$ Gosselman, 43.
} 
el suroccidente colombiano, registra una protección mejor utilizada por la población local, que consistía en el uso de capas de enea o junco y sombreros de paja ${ }^{67}$ Aún con estos ejemplos de aspectos atractivos para los viajeros, cabe recalcar que sus descripciones no se refieren a inundaciones o a periodos que fueran anormalmente lluviosos. Por el contrario, restaron más atención a las sequías, en especial por los efectos en un país principalmente dedicado a actividades agropecuarias.

Como lo han demostrado en una investigación previa, ${ }^{68}$ una de las sequías más severas que se experimentó en la Sabana de Bogotá durante el siglo XIX fue la ocurrida entre 1822 y 1832, interrumpida por breves periodos de lluvias. Por tratarse de la capital, lugar que la mayor parte de viajeros incluía en su itinerario, son mayores las referencias sobre las afectaciones que allí se presentaron, pero no las únicas. En su calidad de miembro de la misión científica francesa que contrató el naciente gobierno republicano, Jean Baptiste Boussingault tomó algunos registros de temperatura, presión atmosférica y precipitaciones. Sin embargo, esta recopilación no fue continua ni siempre tomada con instrumentos meteorológicos. La precipitación, por ejemplo, no es calculada en milímetros ni cubre los más de 10 años que estuvo en el país, sino que se limita a algunos meses de 1823 cuando describe la nubosidad y anota los días de lluvia (desde llovizna hasta el aguacero torrencial). Esta información se reúne en la figura 2 .

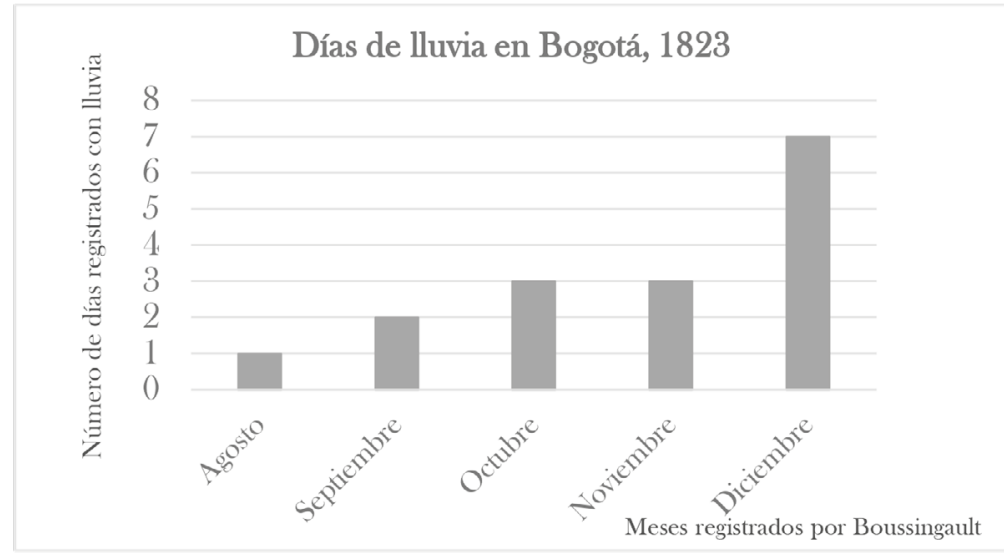

Figura 2. Días de lluvia en Bogotá, agosto a diciembre de 1823, según Boussingault

Fuente: Elaboración propia con base en los datos de Boussingault ${ }^{69}$.

Aunque la información cuantitativa de Boussingault sea limitada, es de resaltar que, en 153 días de observaciones, solo se presentaron 16 días de lluvia en la capital (incluyendo lloviznas ligeras) y que los meses que en condiciones habituales

\footnotetext{
${ }^{67}$ Hamilton, Viajes por el interior de las provincias de Colombia, 1955, II:11, 74.

${ }^{68}$ Mora Pacheco, Entre sequías, heladas e inundaciones.

${ }^{69}$ Boussingault y Roulin, Viajes cientificos a los Andes ecuatoriales, 270-74.
} 
son los más lluviosos del año (octubre y noviembre), no se superaron los 3 días de lluvia y las precipitaciones estuvieron por debajo del mes de diciembre, habitualmente seco. Si bien la observación de las precipitaciones no continúa después de enero de 1824, a través de las Memorias de Boussingault se evidencia que la sequía continuaba en febrero y marzo de 1825 , cuando rememora que

hubo una sequía extraordinaria. Las cosechas se perdían, se hacían procesiones y plegarias para conseguir lluvias [...] En Bogotá se declararon varias oftalmias debidas a la sequedad de la atmósfera y a la reverberación del piso [...] La piel del rostro se torna quebradiza, los labios sangran si no se toman las precauciones para evitar los efectos de la insolación. Creí mi deber seguir atentamente la marcha del higrómetro durante el periodo de sequía que atravesábamos. ${ }^{70}$

En esos registros con el higrómetro la humedad relativa solo superó el 80\% en la tarde del 2 de marzo, sin que se presentaran lluvias, mientras son frecuentes los días con una humedad inferior al $60 \%$ o casos críticos como el del 9 de marzo, el día más seco de sus mediciones, cuando la humedad descendió hasta $24 \%$ a mediodía, condición que hacía difícil respirar. ${ }^{71}$ Esta misma ausencia de lluvias en Bogotá durante los primeros meses de 1825 fue anotada por Hamilton, quien también registró la celebración de rogativas, en este caso a Santa Bárbara, ${ }^{72}$ pero considerando que "la santa era dura de corazón e inconmovible a las súplicas, pues durante todo este tiempo no cayó una sola gota de agua". ${ }^{73} \mathrm{Y}$ ampliaba:

Al prolongarse inclemente la sequía, reses y ovejas morían por falta de aguas y de pastos y gran número de campesinos que habitan la Sabana de Bogotá, se veían obligados a abandonar sus aldeas, para llevar sus ganados a las tierras bajas cercanas a los grandes ríos. Para implorar remedio a tal calamidad, se acudió al expediente de bajar a la ciudad un santo, abogado de los labradores, que se conservaba en un nicho de la iglesia de Monserrate, el cual fue llevado varias veces en procesión por las calles seguido de gran copia de frailes, sacerdotes y nutrida muchedumbre; pero todo fue en vano, y tuvimos que seguir soportando un sol achicharrante sin pisca de lluvia si se exceptúa, en alguna ocasión, un ligero cernidillo. ${ }^{74}$

Pero la capital no era la única zona afectada. A su llegada al país en 1825 , Gosselman desembarcó en Cartagena y destacó las afectaciones de "dos años de sequía que habían dejado marchito el paisaje y exterminado todo el verdor, con la sola excepción de las palmeras que hacían virar sus largas y débiles ramas sobre las casas entre blancas y grises, dándoles una leve protección contra los rayos de sol que caían

\footnotetext{
${ }^{70}$ Jean Baptiste Boussingault, Memorias, vol. 1 (Bogotá: Banco de la República, 1994), 358, 359.

${ }^{71}$ Boussingault, 1:359-61.

72 Para más información sobre el culto a esta santa y su vinculación con fenómenos meteorológicos, ver Francisco González López, ;A esta santa Bárbara jamás me encomendé! Los giros de la iconografia de santa Bárbara en la Nueva Granada (Bogotá: Universidad del Rosario, 2020).

${ }^{73}$ John Potter Hamilton, Viajes por el interior de las provincias de Colombia, vol. I, Archivo de la Economía Nacional 15 (Bogotá: Imprenta del Banco de la República, 1955), 125.

${ }^{74}$ Hamilton, Viajes por el interior de las provincias de Colombia, 1955, II:130.
} 
perpendiculares y ardientes". ${ }^{75}$ La sequía se interrumpió el 15 de abril por un aguacero torrencial "de estilo tropical, que quería, si era posible, reponer de una vez los dos años de sequía [que permitió] repletar los estanques de la mayoría de las casas, que, durante mucho tiempo por falta del elemental líquido, no habían logrado cumplir con su función, cual era surtir a la ciudad de agua potable". ${ }^{76}$

A principios de 1825, de nuevo Hamilton registraba una sequía al regresar de un recorrido por diferentes poblaciones de la "tierra caliente" como Tocaima, Purificación e Ibagué. En Tocaima, encontró pérdidas de las cosechas de maíz, plátano y cacao, por ausencia de las lluvias de la temporada marzo-abril de 1824 y la continua sequía, que incluso había llevado a muchos a morir de hambre o, si tenían los medios, a conseguir comida a precios elevados en la Sabana de Bogotá y otras provincias que no especifica. ${ }^{77} \mathrm{Al}$ pasar por la villa de Purificación (hoy Tolima) anota que, a diferencia del momento de su llegada, el río Magdalena "estaba bastante bajo debido a la larga sequía". ${ }^{78}$ Sin embargo, la ausencia de lluvias no era total porque menciona que el calor era insoportable aun pasada la lluvia y que se pudieron refrescar en un río. Los primeros días de enero de 1825, en los alrededores de Ibagué, describe la zona como "cubierta de altos pastos y bien provista de ganados, aunque escasa de aguas, debido, probablemente, a la prolongada sequía" ${ }^{79}$ La viuda que lo hospeda, a orillas del río, le informa que había perdido sus cosechas por la sequía en una época que normalmente era de invierno y que, en contraste, en el área del Quindío, la humedad sí había sido suficiente para alimentar los cultivos de plátano y maíz. En los últimos meses de 1824, él mismo había constatado que, en contraste, las áreas vecinas a Popayán y Pasto estaban afectadas por torrenciales lluvias, caminos fangosos y ríos crecidos. Esta disímil situación en el territorio nacional es propia de los eventos ENOS que afectan en forma desigual de acuerdo con las condiciones biofísicas locales que los experimentan.

Por último, entre los viajeros coincidentes con ocurrencia de ENOS, se encuentra Ernst Röthlisberger. De su viaje de ingreso por el bajo Magdalena, en Año Nuevo de 1882 recuerda el escaso caudal del río que no permitía el avance de su embarcación, al punto que, los marineros calcularon tres pies de profundidad y decidieron detenerse por completo. Considera que queda preso en una "calurosa cárcel [...] Cuatro días eternamente largos duró aquel martirio, a una temperatura sugeridora de ideas suicidas, ;entre $\operatorname{los} 38^{\circ} \mathrm{C}$ y $39^{\circ} \mathrm{C}$ a la sombra! Ya no sé exactamente cómo pasé todo aquello; mis compañeros de viaje, en particular el señor ministro Cané, estaban del más negro humor". Finalmente los rescata un barco de muy poco calado que había partido de Barranquilla el 31 de diciembre, seis días después que el suyo, $\mathrm{y}$, por sus características puede avanzar por el disminuido río. ${ }^{80}$ La mayor parte de los

\footnotetext{
${ }^{75}$ Gosselman, Viaje por Colombia, 1825 y 1826, 25.

${ }^{76}$ Gosselman, 43.

${ }^{77}$ Hamilton, Viajes por el interior de las provincias de Colombia, 1955, I:151.

${ }^{78}$ Hamilton, I:157.

${ }^{79}$ Hamilton, Viajes por el interior de las provincias de Colombia, 1955, II:122.

${ }^{80}$ Röthlisberger, El Dorado, 1:42.
} 
años que vive en el país los pasa en Bogotá y cuando describe su clima, no refiere alguna sequía particular, pero sí menciona que a veces la temporada seca, que debería terminar en septiembre con frecuencia "se continúa hasta el mismo mes de octubre, de modo que la Sabana aparece agostada y los ganados se debilitan y enflaquecen terriblemente a causa de la falta de agua". ${ }^{81}$

Pero no todos los años identificados como ENOS $^{82}$ coinciden con visitas de viajeros que publicaran sus diarios. Asimismo, no todas las sequías registradas por viajeros coinciden con años reconocidos como ENOS, sino que pueden obedecer a condiciones locales o servir de guía para la futura identificación de teleconexiones en el estudio sobre fenómenos de carácter global, vinculados a ENOS o no. Tales son los casos de las observaciones del inglés Joseph Brown y del español José María Gutiérrez de Alba. En febrero de 1834, Brown, en su camino de Bogotá a Girón, describe un día

en extremo bochornoso y el calor se hacía opresivo, casi sofocante, marchitándolo todo bajo su poder [...] La acción del sol sobre la piel hace que el tránsito en el calor del día a través de estas altiplanicies sea sumamente desagradable y si no se lleva una máscara de lienzo sobre la cara, costumbre adoptada por la mayoría de viajeros, se puede tener por consecuencia cierta un cambio completo de piel, que muda hacia el segundo o tercer día con tanta claridad como puede verse la misma operación por las serpientes..$^{83}$

En su paso por Zipaquirá, describió un sol "extremadamente cálido" y unos campos que eran testimonio de "la larga duración de la última y prolongada sequía"; más adelante, al llegar a la laguna de Fúquene encuentra que "el agua había retrocedido mucho por consecuencia del tiempo excesivamente seco [aunque] todavía cubría muchas leguas". ${ }^{84}$ A principios de marzo, cuando llega a Socorro, encuentra

todas las montañas de los alrededores incendiadas por la circunstancia del tiempo excesivamente seco, proporcionándose los agricultores los medios de despejar de matorrales, por medio del fuego, las laderas de la sierra y, haciendo esto, conseguir más terreno disponible para el cultivo. En la noche presentaba un bello efecto que me recordaba las almenaras de los montañeses escoceses durante la guerra de los invasores ingleses. ${ }^{85}$

\footnotetext{
${ }^{81}$ Röthlisberger, 1:75.

${ }^{82}$ Jöelle L Gergis y Anthony M. Fowler, “A history of ENSO events since A.D. 1525: implications for future climate change", Climatic Change 92 (2009): 343-87; César Caviedes, El Niño in history. Storming through the ages (Gainesville (Florida): University Press of Florida, 2001); Anne-Marie Hocquenghem y Luc Ortlieb, "Eventos El Niño y lluvias anormales en la costa del Perú: siglos XVI-XIX", Bulletin de l'Institut français d'études andines 21, n. ${ }^{\circ} 1$ (1992): 197-278; William Quinn y Víctor Neal, "The historical record of El Niño events", en Climate since A.D.1500, ed. R. S Bradley y P. D Jones (Nueva York: Routledge, 1995), 623-48.

${ }^{83}$ Joseph Brown, Tipos y costumbres de la Nueva Granada. La colección de pinturas formada en Colombia por Joseph Brown entre 1825 y 1841 y el diario de su excursión a Girón, 1834, ed. Malcom Deas, Efraín Sánchez, y Martínez (Bogotá: Fondo Cultural Cafetero, 1989), 152.

${ }^{84}$ Brown, 156, 157.

${ }^{85}$ Brown, 201.
} 
Sin embargo, hasta el momento no se han encontrado otros datos que permitan establecer la duración de estas sequías, ni si se trataban de un fenómeno atípico o solo eran manifestaciones esperadas del habitual periodo seco que en los Andes Orientales va de diciembre a principios de marzo.

Por su parte, el español José María Gutiérrez de Alba, se ve afectado por una sequía en el Valle de Leyva en 1872. Por sus conocimientos sobre agricultura, fue contratado como asesor para establecer en los valles de Leiva, Ráquira y Sutamarchán el cultivo en gran escala de olivo, vid y otras plantas de países meridionales de Europa que no especifica ${ }^{86}$. Entre abril y junio, meses habitualmente lluviosos, pese a tener dispuesto el terreno y los árboles, no podía llevar a cabo las "labores preparatorias para la plantación" porque aún no se presentaban las lluvias, "sin las cuales nada puede hacerse, por lo compacto y duro del terreno, que desde tiempo inmemorial no se ha roturado". ${ }^{87}$ Regresó a Bogotá a resolver otros asuntos y solo hasta agosto registró que se habían presentado algunas lluvias en el valle de Leyva, pero el motivo para no emprender la siembra fue otro: no se pudieron pactar las condiciones del contrato. ${ }^{88}$

\section{Consideraciones finales}

Los relatos de viaje no solo dan cuenta del asombro y repulsión que ciertas condiciones climáticas del país generaban en los extranjeros. Aunque mediadas por sus interpretaciones o la distancia entre el hecho y el momento de la escritura, también contienen visiones de la población local sobre ese mundo lejano del cual se informaban por las descripciones foráneas. En otras palabras, el extrañamiento era mutuo. Por otra parte, las similitudes que la mayoría de los viajeros encontraron entre los Andes colombianos y sus lugares de origen, no solo en términos climáticos, sino antrópicos, permite, una vez más, ampliar el rango de alcance de aquellos espacios donde los europeos pudieron recrear su mundo en su expansión por el planeta entre los siglos XVI y XIX. Las "Nuevas Europas” también pueden encontrarse en los Andes nororientales.

De igual manera, y aunque no es el tema del artículo, por otras investigaciones en curso en donde se estudian relatos de viaje de colombianos por el territorio nacional, y literatura colombiana decimonónica, las percepciones que tenían los nacionales sobre el clima en cuanto a la relación de este con los pisos térmicos no varía mucho a la que tenían los extranjeros. Las zonas altas eran de temperaturas afables mientras que las zonas bajas eran inclementes. Esto también permitió construir una idea de civilización ligada a la temperatura, en donde zonas como la Sabana de Bogotá eran escenarios acordes para que aquella se manifestara, en contravía de lo que sucedía en la denominada "tierra caliente". Esta coincidencia, entre colombianos y extranjeros, en la forma de ver y entender el clima es un tema al que aún le queda mucho por investigar.

\footnotetext{
${ }^{86}$ José María Gutiérrez de Alba, Impresiones de un viaje a América (Bogotá: Villegas Editores, 2012 ), 235.

${ }^{87}$ Gutiérrez de Alba, 236.

${ }^{88}$ Gutiérrez de Alba, 240.
} 
Ejemplo de lo anterior es el payanés Manuel Pombo quien, en 1852, y después de participar en la guerra civil de 1851 en el ejército vencedor, se desplazó de Medellín a Bogotá. En su relato de viaje Pombo describe cómo el cambio de vegetación es muestra del cambio de clima: "íbamos ascendiendo suavemente hacia la región de la nieve [refiriéndose a Herveo]. La vegetación decrecía y escaseaba, reducida ya a arbustos y chaparrales". ${ }^{89}$ Mientras que, las zonas de tierras bajas, es decir la "tierra caliente", se caracterizaba por sus "selvas achicharradas y sus llanuras áridas", y por ser la tierra del "jaguar y de los caimanes, de la venenosa culebra" ${ }^{90}$ Medardo Rivas también discurre sobre la "tierra caliente", zona de baja altitud sobre el nivel del mar en donde la civilización, representada en personas como él, y que desciende de las tierras altas, específicamente de la Sabana de Bogotá, tiene una labor encomiable, la de confrontar y vencer a la barbarie de esa "tierra caliente" y convertirla, junto con sus habitantes a la civilización ligada con el progreso. ${ }^{91}$

Como los dos autores mencionados, otros más plasmaron en sus obras literarias lo que a lo largo del artículo hemos mostrado; por ejemplo, Eugenio Díaz (Manuela, 1858; El rejo de enlazar, 1973 - póstuma); Luis Segundo de Silvestre (Tránsito, 1886); Soledad Acosta de Samper (Una holandesa en América, 1888); José Manuel Marroquín (El Moro, 1896), además de la compilación que hizo José María Vergara y Vergara de casi cien cuadros de costumbres en El museo de cuadros de costumbres y variedades (1866). En todas y cada una de estas obras, y en otras más, los autores mostraron, igual que los viajeros extranjeros, el problema de la relación entre el clima, sobre todo vinculado con la altitud, con el paisaje y las comodidades del escenario. Por tratarse de autores nacionales, ya no extranjeros, se abre la cuestión para seguir indagando sobre la coincidencia de los puntos de vista y de apreciaciones entre unos y otros. Aunque se haya avanzado en la reconstrucción de las percepciones del clima por parte de algunos autores colombianos en el siglo XIX, la comparación con los textos de viajeros extranjeros sigue siendo aún un campo por arar. ${ }^{92}$

En cuanto a las “anomalías” meteorológicas, las sequías fueron más llamativas que las inundaciones por el impacto evidente en las actividades agropecuarias de las cuales dependía por entonces un país eminentemente rural. Sin embargo, aunque a lo largo del siglo XIX pudieron presentar muchas más sequías, y más severas de las que aquí se recogen, fueron muy pocos los viajeros que registraron estos fenómenos. Las razones son varias. Primero, en varios lapsos la presencia de viajeros disminuye y hasta parece desvanecerse del todo, tal como ocurre entre 1840 y 1850 o de 1853 a 1869. Segundo, varios de los relatos son producto de estancias muy cortas que no permitieron apreciar situaciones excepcionales. Por esta razón, los relatos de viajeros no pueden ser tomados como único referente para la reconstrucción de las sequías y deben complementarse con estudios geográficos y prensa de la época.

\footnotetext{
${ }^{89}$ Manuel Pombo, De Medellín a Bogotá (Bogotá: Biblioteca V Centenario, Colcultura, 1992) 132.

${ }^{90}$ Pombo, 153-154.

${ }^{91}$ Medardo Rivas, Los trabajadores de tierra caliente (Bogotá: Imprenta y Librería de M. Rivas, 1899).

${ }^{92}$ Felipe Martínez-Pinzón, "La mirada invernocular: clima y cultura en Colombia (1808-1924)"
} 
Por último, es de interés el énfasis que muchos de los viajeros pusieron en la relación entre clima y trabajo, clima y enfermedad, clima y potencialidades para la agricultura y la explotación forestal. En no pocos casos, estas descripciones buscaban abrir un panorama de inversión para las potencias de las cuales eran emisarios o para sus compatriotas. Sin embargo, cabe preguntarse por qué, tampoco con esta promoción de las potencialidades del territorio colombiano, se logró atraer la anhelada inversión extranjera o la migración masiva de nuevos pobladores.

\section{Bibliografía}

\section{Fuentes secundarias}

\section{Libros}

Antei, Giorgio. Guía de forasteros: viajes ilustrados por Colombia, 1817-1857. Bogotá: Seguros Bolívar, 1995.

Bache, Richard. Notes on Colombia: taken in the years 1822-3 with an itinerary of the route from Caracas to Bogotá and appendix. Filadelfia: H.C. Carey, 1827.

Betancourt Echeverry, Darío. Reseña histórica de la meteorología en Colombia. Bogotá: HIMAT, 1982.

Boussingault, Jean Baptiste. Memorias. Vol. 1. 3 vols. Bogotá: Banco de la República, 1994.

Boussingault, Jean Baptiste, y Francois Desiré Roulin. Viajes científicos a los Andes ecuatoriales o colección de memorias sobre física, química é historia natural de la Nueva Granada, Ecuador y Venezuela. Traducido por Joaquín Acosta. Bogotá: Instituto Colombiano de Cultura Hispánica, 1849.

Brown, Joseph. Tipos y costumbres de la Nueva Granada. La colección de pinturas formada en Colombia por Joseph Brown entre 1825 y 1841 y el diario de su excursión a Girón, 1834. Editado por Malcom Deas, Efraín Sánchez, y Martínez. Bogotá: Fondo Cultural Cafetero, 1989.

Cané, Miguel. En viaje. Caracas: Biblioteca Ayacucho, 2005.

Carnegie-Williams, Rosa. Un año en los Andes o aventuras de una lady en Bogotá. Bogotá: Tercer Mundo Editores - Academia de Historia de Bogotá, 1990.

Caviedes, César. El Niño in history. Storming through the ages. Gainesville (Florida): University Press of Florida, 2001. 
Cochrane, Charles Stuart. Journal of a residence and travels in Colombia during the years 1823 and 1824. Vol. 1. 2 vols. Londres: Henry Colburn, 1825.

Codazzi, Agustín. Geografía física y política de la Confederación Granadina. Bogotá: Universidad Nacional de Colombia, 2003.

Crosby, Alfred. The Columbian exchange: biological and cultural consequences of 1492. Connecticut: Greenwood Press, 1972.

Deas, Malcom, Efraín Sánchez, y Martínez, eds. Tipos y costumbres de la Nueva Granada. La colección de pinturas formada en Colombia por Joseph Brown entre 1825 y 1841 y el diario de su excursión a Girón, 1834. Bogotá: Fondo Cultural Cafetero, 1989.

D’Espagnat, Pierre. Recuerdos de la Nueva Granada. Bogotá: Ediciones Guadalupe, 1971.

Díaz Granados, José Luis. Viajeros extranjeros por Colombia. Bogotá: Presidencia de la República, 1997.

Duane, William. Viaje a la Gran Colombia en los años 1822-1823. Vol. 2. 2 vols. Caracas: Instituto Nacional de Hipódromos, 1968.

Empson, Charles. Narratives of South America: illustrating manners, customs, and scenery: containing also numerous facts in natural history, collected during a four years' residence in tropical regions. Londres: Published for the author by W. Edwards, 1836.

González López, Francisco. ¡A esta santa Bárbara jamás me encomendé! Los giros de la iconografía de santa Bárbara en la Nueva Granada. Bogotá: Universidad del Rosario, 2020.

Gosselman, Carl August. Viaje por Colombia, 1825 y 1826. Archivo de la Economía Nacional 41. Bogotá: Ediciones del Banco de la República, 1981.

Guhl, Ernesto. Colombia. Bosquejo de su geografia tropical. Vol.1 Geografia Física (Edición Conmemorativa). Bogotá: Universidad Nacional de Colombia Universidad de los Andes - Jardín Botánico de Bogotá José Celestino Mutis, 2016.

Gutiérrez de Alba, José María. Impresiones de un viaje a América. Bogotá: Villegas Editores, 2012.

Hall, Francis. Colombia: its present state, in respect of climate, soil, productions, populations, populations, government, commerce, revenue. Londres: Baldwin, 1827. 
Bajo el sol ardiente y la lluvia torrencial. Viajeros extranjeros y clima colombiano en el siglo...

Hamilton, John Potter. Viajes por el interior de las provincias de Colombia. Vol. I. II vols. Archivo de la Economía Nacional 15. Bogotá: Imprenta del Banco de la República, 1955.

Hamilton, John Potter. Viajes por el interior de las provincias de Colombia. Vol. II. II vols. Archivo de la Economía Nacional. Bogotá: Imprenta del Banco de la República, 1955.

Hamilton, John Potter. Viajes por el interior de las provincias de Colombia. Vol. I. II vols. Archivo de la Economía Nacional 15. Bogotá: Imprenta del Banco de la República, 1955.

Hamilton, John Potter. Viajes por el interior de las provincias de Colombia. Bogotá: Presidencia de la República - Colcultura - Biblioteca Nacional de Colombia, 1993.

Hettner, Alfred. Viajes por los Andes Colombianos (1882-1884). Bogotá: Publicaciones del Banco de la República - Archivo de la Economía Nacional, 1976.

Holton, Isaac. La Nueva Granada: veinte meses en los Andes. Bogotá: Ediciones del Banco de la República, 1981.

Le Moyne, Augusto. Viajes y estancias en la América del Sur. La Nueva Granada, Santiago de Cuba, Jamaica y el Istmo de Panamá. Bogotá: Biblioteca Popular de la Cultura Colombiana, 1945.

Lisboa, Miguel María. Relación de un viaje a Venezuela, Nueva Granada y Ecuador. Bogotá: Fondo Cultural Cafetero, 1984.

Lisboa, Miguel María. Relación de un viaje a Venezuela, Nueva Granada y Ecuador. Caracas: Biblioteca Ayacucho, 1992.

Mollien, Théodore Gaspard. Viaje por la República de Colombia. Bogotá: Biblioteca Popular de la Cultura Colombiana, 1944.

Mora Pacheco, Katherinne. Entre sequias, heladas e inundaciones. Clima y sociedad en la Sabana de Bogotá, 1690-1870. Bogotá: Universidad Nacional de Colombia, 2019.

Nieto, Mauricio. Orden natural y orden social ciencia y política en el semanario del Nuevo Reino de Granada. Bogotá: Universidad de los Andes, 2008.

Pérez, Felipe. Geografía general física y política de los Estados Unidos de Colombia y geografia particular de la ciudad de Bogotá. Bogotá: Imprenta de Echeverría Hermanos, 1883. 
Pombo, Manuel. De Medellín a Bogotá. Bogotá: Biblioteca V Centenario - Colcultura, 1992.

Pratt, Mary Louise. Ojos imperiales. Literatura de viajes y transculturación. México: Fondo de Cultura Económica, 2010.

Rivas, Medardo. Los trabajadores de tierra caliente. Bogotá: Imprenta y Librería de M. Rivas, 1899.

Romero, Mario Germán, ed. Bogotá en los viajeros extranjeros del siglo XIX. Bogotá: Alcaldia Mayor de Bogotá - Villegas Editores, 1990.

Röthlisberger, Ernst. El Dorado. Estampas de viaje y cultura de la Colombia suramericana. Vol. 1. 2 vols. Apuntes maestros. Bogotá: Universidad Nacional de Colombia, 2016.

Steuart, John. Narración de una expedición a la capital de la Nueva Granada y residencia allí de once meses (Bogotá en 1836-37). Bogotá: Academia de Historia de Bogotá - Tercer Mundo Editores, 1989.

\section{Capítulos de libros}

Quinn, William, y Víctor Neal. "The historical record of El Niño events". En Climate since A.D.1500, editado por R. S Bradley y P. D Jones, 623-48. Nueva York: Routledge, 1995.

Uribe Martínez, Simón. "Construyendo el trópico: relatos de viajeros ingleses en Colombia durante el siglo XIX”. En Semillas de historia ambiental, editado por Stefania Gallini, 215-50. Bogotá: Universidad Nacional de Colombia-Jardín Botánico de Bogotá, 2015.

\section{Artículos de revistas}

Gergis, Jöelle L, y Anthony M. Fowler. “A history of ENSO events since A.D. 1525: implications for future climate change". Climatic Change 92 (2009): 343-87.

Guerra, Adriano. "El imperio invisible. Los mosquitos en el Caribe colombiano vistos por los viajeros extranjeros del siglo XIX". Memorias. Revista digital de Historia y Arqueología desde el Caribe colombiano 41 (2020): 103-29. https://doi. org/10.14482/memor.41.986.1.

Hocquenghem, Anne-Marie, y Luc Ortlieb. "Eventos El Niño y lluvias anormales en la costa del Perú: siglos XVI-XIX”. Bulletin de l'Institut français d'études andines 21, 1 (1992): 197-278.

Jaramillo Uribe, Jaime. "La visión de los otros. Colombia vista por observadores extranjeros en el siglo XIX". Historia Crítica, 24 (2003): 7-21. 
Mora Pacheco, Katherinne. "Tras la pista de "terribles veranos" y "copiosas lluvias". Elementos para una historia climática del territorio colombiano". Historia Crítica 74 (2019): 19-40. https://doi.org/10.7440/histcrit74. 2019.02.

Mora Pacheco, Katherinne Giselle. "Monotonía, aislamiento y atraso agrícola. Descripciones de viajeros del siglo XIX e historia agraria de la Sabana de Bogotá (Colombia)". HiSTOReLo. Revista de historia regional y local 7, n. ${ }^{\circ} 14$ (2015): 180-213. http://dx.doi.org/10.15446/historelo.v7n14.48625.

Mörner, Magnus. "Viajeros e inmigrantes europeos como observadores e intérpretes de la realidad latinoamericana del siglo XIX". En Observation and Communication: the construction of realities in the Hispanic World, 415-30. Estocolmo: Institute of Latin American Studies, 2000.

Nieto, Mauricio, Paola Castaño, y Diana Ojeda. ““'El influjo del clima en los seres organizados" y la retórica ilustrada en el Semanario del Nuevo Reyno de Granada". Historia Crítica 30 (2005): 91-114.

Pabón Caicedo, José Daniel. "El clima de Colombia durante los siglos XVI-XIX a partir de material histórico. Parte I: Inventario de fuentes de información". Cuadernos de Geografia 15 (2006): 75-92.

Pabón Caicedo, José Daniel, y Germán Torres. "Impacto socioeconómico de los fenómenos El Niño y La Niña en la Sabana de Bogotá durante el siglo XX". Cuadernos de Geografía 16 (2007): 81-94.

Poveda, Germán, Peter Waylen, y Roger S Pulwarty. "Annual and inter-annual variability of the present climate in northern South America and southern Mesoamerica". Palaeogeography, Palaeoclimatology, Palaeoecology 234, 1 (2006): 3-27.

\section{Tesis, ponencias y otros}

Martínez-Pinzón, Felipe. "La mirada invernocular: clima y cultura en Colombia (1808-1924)". Tesis Doctor of Philosophy, New York, New York University, 2012.

Torres Torres, Camila. "La imagen de Bogotá construida por los viajeros extranjeros que recorrieron el país a lo largo del siglo XIX". Tesis de Maestría en Historia, Pontificia Universidad Javeriana, 2009. http://repository.javeriana.edu.co/ handle/10554/458. 